\section{Digestibilidade (aparente) de feno de Cunhã (Clitoria ternatea Linn) em dois estádios vegetativos com ovinos (Ovis aries L.)*}

\author{
Apparent digestibility of Cunhã (Clitoria ternatea Linn) \\ hay at two maturity stages in sheep (Ovis aries $L$.)
}

Ana Helena Macedo GOUVEA '; Cassio Xavier de MENDONÇA JUNIOR ; Carlos de Sousa LUCCI ${ }^{2}$; Laércio MELOTTI ${ }^{2}$
CORRESPONDENCE TO

\title{
RESUMO
}

Foram utilizados doze ovinos mestiços, machos inteiros, com idade média de 17 meses, em ensaio de digestibilidade aparente, segundo delineamento inteiramente casualizado, com dois tratamentos para avaliar-se o feno de Cunhã (Clitoria ternatea L.) cortados com A) 60 dias B) 90 dias de idade vegetativa. Os resultados deste ensaio permitiram concluir que os coeficientes de digestibilidade da matéria seca, fibra bruta, extrato etéreo e o teor de N.D.T. (nutrientes digestíveis totais) foram mais elevados para o feno cortado aos 90 dias, porém a digestibilidade dos extrativos não nitrogenados foi melhor para o feno de 60 dias, enquanto que a digestibilidade da proteína foi semelhante para os dois fenos. Concluiu-se que a Cunhã cortada aos 90 dias de crescimento continua a fornecer feno de boa qualidade.

UNITERMOS: Digestibilidade; Ovinos; Feno.

\section{INTRODUCĀO}

A cunhã (Clitoria ternatea L.) é uma leguminosa, semi-arbustiva, perene, rastejante ou trepadeira, podendo alcançar até cinco metros de extensão (Cronquist ${ }^{7}, 1968$ ). Tem sido largamente distribuída nas zonas tropical e sub-tropical de ambos os hemisférios (Sanchez ${ }^{18}, 1969$ ), mostrando preferência pelo trópico seco e sub-úmido (Garza et al. ${ }^{10}$, 1972).

O gênero Clitoria ternatea é representado por mais de 30 espécies (Bailey ${ }^{4}, 1949$; Crowder ; 1974). A cunhã é considerada como forragem com boa cobertura, sendo apropriada para o cultivo irrigado ou condições de alguma umidade (Chakravarty6, 1970). No entanto, Gurgel; Fernandes ${ }^{12}$ (1980) verificaram que ela está entre as leguminosas mais hábeis para sobreviver na estação seca do Ceará, produzindo grande quantidade de matéria seca (MS) e sementes, e apresentando alto valor nutritivo.

Katiyar et al.13 (1970) realizaram experimentos com Clitoria lernatea, em estádio vegetativo de cerca de 2 meses, como forragem verde e na forma de feno, em ensatio de digestibilidade com carneiros e encontraram para o feno uma composição química de: $80,5 \%$ de MS; $22,5 \%$ de PB; $3,2 \%$ de EE; $33,4 \%$ de $\mathrm{FB} ; 32,8 \%$ de ENN e $8,1 \%$ de MM. Os coeficientes de digestão (CD) para o feno foram 74,9\% para MS: $84,8 \%$ para $\mathrm{PB} ; 61,6 \%$ para $\mathrm{EE} ; 65,9 \%$ para $\mathrm{FB}$ e

* Traballho apresentado como dissertação para oblenção do lílulo de mestrado pela Faculdade de Medicina Veterinária e

Zootecnia da USP
$76,8 \%$ para ENN.

Ram Ratan et al. ${ }^{17}$ (1982) conduziram experimento com a cunhã na forma de feno para determinar seu valor nutritivo através da digestibilidade com carneiros. A forragem foi cortada nos estádios de pré-floração, floração e em início de formação de vagens, convertida em feno e misturada. A composição química do feno de Cunhã foi de $94,0 \%$ de MS; $15,3 \%$ de PB; $2,3 \%$ de EE; $32,2 \%$ de FB; $42,7 \%$ de ENN e $7,4 \%$ de cinzas. Os coeficientes de digestibilidade foram de $60.5 \%$ para $\mathrm{MS} ; 74,4 \%$ para $\mathrm{PB} ; 33,7 \%$ para $\mathrm{EE} ; 49,3 \%$ para FB e $71,6 \%$ para Enn. Upadhyaya; Pachauri ${ }^{19}$ (1983) realizaram ensaio de digestibilidade do feno de Cunhã com càprinos. Encontraram para a composição química do feno os seguintes valores na base seca: $97,6 \%$ de $\mathrm{MS} ; 13,0 \%$ de $\mathrm{PB}$; $2,4 \%$ de EE; $23,6 \%$ de FB e $54,9 \%$ de ENN. Os coeficientes de digestibilidade foram: $59,7 \%$ para $\mathrm{MS} ; 63,8 \%$ para $\mathrm{PB}$; $54,2 \%$ para $\mathrm{EE} ; 37,4 \%$ para $\mathrm{FB}$ e $72,5 \%$ para ENN.

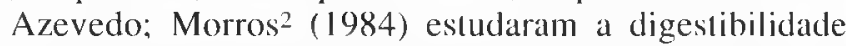
"in vitro" de MS e Matéria Orgânica do feno de Cunhã, em quatro diferentes estádios vegetativos, sendo tratamentos as forragens cortadas nos seguintes períodos: $A=42$ dias; $\mathrm{B}=56$ dias; $\mathrm{C}=70$ dias e $\mathrm{D}=84$ dias. Os autores encontraram os valores em proteína bruta (PB): $13 \%, 10 \%, 10 \%$ e $8 \%$ em FB. $29 \%, 38 \%, 38 \%$ e $39 \%$, respectivamente para os tratamentos $\mathrm{A}, \mathrm{B}, \mathrm{C}$ e $\mathrm{D}$. Com base nesses resultados, foi sugerido que o feno deva ser feito com forragens contando de 42 a 70 dias de idade, sem prejuízo do seu valor nutritivo.

O presente trabalho teve como objetivo estudar o valor nutritivo do feno de cunhã, para avaliar o potencial do seu aproveitamento na nutrição animal. 
GOUVEA, A.H.M.: MENDONÇA JÚNIOR, C.X.; LUCCI, C.S.; MELOTTI, L. Digestibilidade (aparente) de feno de Cunhã (Clihoria termaea Limm) em dois estádios vegetitivos com ovinos (Oı's ariés L.) Braz.. J. vel. Res. anim. Sci., São Paulo, v.33, n.2, p.93-96, 1996.

\section{MATERIAL E MÉTODO}

O feno utilizado no presente experimento foi proveniente de plantio em área do município de Santa Cruz das Palmeiras, SP, que recebeu adubação de $60 \mathrm{~kg}$ de superfosfato simples/ha no momento do plantio e $20 \mathrm{~kg}$ de cloreto de potássio/ha em cobertura, após a germinação. O primeiro corte foi realizado quando a planta tinha 60 dias de crescimento e apresentava altura média de $60 \mathrm{~cm}$; o segundo foi efetuado quando a cultura contava com 90 dias de idade e a altura média era de $90 \mathrm{~cm}$. Os cortes foram realizados manualmente, a uma altura de $10 \mathrm{~cm}$ do solo, sendo a forragem espalhada no campo para murchar durante 4 a 5 horas. Em seguida, foi transferida para um terreno calçado e liso, onde permaneceu exposta ao sol, em leiras frouxas, por um período de 12 horas e revirada por 3 vezes neste período; o término da secagem foi feito à sombra. Após o processo de fenação, os fenos apresentavam coloração verde-clara, com boa proporção de folhas e livres da presença de material estranho. A armazenagem foi realizada em um barracão coberto e arejado, até o início do ensaio de digestibilidade. Este foi conduzido na Faculdade de Medicina Veterinária e Zootecnia da USP, Campus da USP em Pirassununga, SP.

Foram utilizados doze ovinos (Ovis aries L.) machos não emasculados, mestiços das raças Corriedale e Ideal, com idade média de 17 meses, vacinados e vermifugados, que apresentaram peso aproximado de $39 \mathrm{~kg}$ ao início do experimento. Os ovinos permaneceram alojados em gaiolas metabólicas convencionais com arreios de digestibilidade, onde recebiam alimentos, sal mineral e água. $\mathrm{O}$ ensaio de digestibilidade teve duração de 21 dias com duas fases distintas: a pri-

\section{Tabela 1}

Consumo de MS por indivíduo, nos tratamentos estudados, por quilo de peso e por quilo de peso metabólico (peso 0.75). Pirassununga - SP. abril/maio de 1985.

\begin{tabular}{ccccc}
\hline \multirow{2}{*}{ Tratamentos } & animais & \multicolumn{3}{c}{ Consumo de matéria seca } \\
\cline { 3 - 5 } & & $\mathrm{kg} / \mathrm{animal}$ & $\mathrm{kg} / \mathrm{kg} \mathrm{PV}$ & $\mathrm{kg} / \mathrm{kg} \mathrm{PM}$ \\
\hline & 1 & 0,813 & 0,027 & 0,063 \\
$\mathrm{~A}$ & 2 & 0,863 & 0,020 & 0,052 \\
& 3 & 0,835 & 0,020 & 0,051 \\
& 4 & 0,845 & 0,020 & 0,051 \\
& 5 & 0,839 & 0,020 & 0,051 \\
& 6 & 0,839 & 0,019 & 0,049 \\
& $\mathrm{x}$ & $0,839 \pm 0,023^{*}$ & $0,021 \pm 0,001$ & $0,053 \pm 0,002$ \\
& 7 & 0,753 & 0,021 & 0,051 \\
& 8 & 0,630 & 0,016 & 0,040 \\
B & 9 & 0,812 & 0,019 & 0,049 \\
& 10 & 0,821 & 0,019 & 0,049 \\
& 11 & 0,804 & 0,020 & 0,050 \\
& 12 & 0,836 & 0,019 & 0,049 \\
& $x$ & $0,776 \pm 0,023$ & $0,019 \pm 0,001$ & $0,048 \pm 0,002$ \\
\hline média \pm erro padrão da médla & & & &
\end{tabular}

meira de adaptação dos animais às gaiolas e ao alimento, com duração de 14 dias e a segunda com duração de 7 dias, correspondente à colheita de fezes conforme o descrito por Melotti; Luccil4 (1969), mantendo-se sempre as ingestões do volumoso "ad libitum".

Das fezes colhidas no período experimental foram tomadas alíquotas que, ao final do ensaio, foram levadas à estufa com ventilação forçada a $65^{\circ} \mathrm{C}$, por 72 horas, para determinação da MS e encaminhamento para análises químicas. Estas compreenderam a determinação de MS, PB, EE, MM e ENN, seguindo-se as normas da Association of Official Analytical Chemists ${ }^{1}$ (1975).

O delineamento experimental adotado foi o inteiramente casualizado, com dois tratamentos e seis repetições por tratamento (Gomes'1, 1981). Os tratamentos consistiram de A: feno da forragem cortada aos 60 dias e B: feno da forragem cortada aos 90 dias.

\section{RESULTADOS E DISCUSSĀOO}

A Tab. 1 mostra o consumo de matéria seca apresentado pelos animais, durante o período experimental.

O consumo de matéria seca não apresentou diferenças estatisticamente significativas entre os tratamentos e ficou entre $1,9 \%$ (tratamento B) e $2,1 \%$ (tratamento A) como porcentagens do peso vivo, valores em concordância com as exigências apresentadas por ovinos (NATIONAL RESEARCH COUNCIL 16,1976$)$.

Os resultados das análises bromatológicas dos fenos e os coeficientes de digestão estão na Tab. 2.

Os teores de MS dos fenos (próximos a $88 \%$ ) foram considerados ótimos para a conservação da forragem. Os níveis de $\mathrm{PB}$ de $21,7 \%$ trat. (A) e de $19,9 \%$ trat. (B) foram próximos aos encontrados por Katiyar el al. ${ }^{13}(1970), 22,6 \%$ para feno com cerca de 60 dias, superiores aos valores consignados por Ram Ratan et al. ${ }^{17}$ (1982) de $15,3 \%$ de PB em feno cortado em diferentes épocas e àqueles assinalados por Upadhyaya; Pachauri'19 (1983), que auferiram $13,0 \%$ de PB em feno de cunhã em estádio pós-floração.

Os teores de fíbra dos fenos utilizados neste experimento foram de $34,6 \%$ (A) e $41,9 \%$ (B) conforme as colocações de Meyer et al. ${ }^{15}$ (1957); Weir et al. ${ }^{20}(1960) \mathrm{e}$ Darlington; Hersberger) (1968). Katiyar et al. ${ }^{13}$ (1970) encontraram $33,4 \%$ de FB no feno de cunhã com aproximadamente 60 dias de idade vegetativa, enquanto que Ram Ratan et al.17 (1982) obtiveram 32,2\% quando cortado em diferentes idades. Upadhyaya; Pachauril9 (1983) registraram $23,6 \%$ em feno dessa leguminosa, quando cortada após a floração. 
GOUVEA, A.H.M.: MENIONÇA JÚNIOR. C.X.; LUCCI. C.S.: MELOTTI, L. Digestibilidade (aparente) de feno de Cunhã (Chitoria ternutea Linn) em dois estádios vegelativos com ovinos (Ovis cires $L$.) Braz. J. vet. Kes. anim. Sci., São Paulo, v.33, n.2, p.93-96, 1996.

\section{Tabela 2}

Composição bromatológica dos fenos de Cunhã (Clitória ternatea L.) (\% de M.S.) e coeficientes de digestão (\%). Pirassununga - SP, abril/maio de 1985.

\begin{tabular}{lcllllc}
\hline Tratamentos & MS & PB & FB & ENN & EE & MM \\
\hline Corte aos 60 dias & 88,2 & 21,7 & 34,6 & 30,1 & 3,3 & 10,2 \\
Corte aos 90 dias & 87,9 & 19,9 & 41,9 & 24,5 & 4,2 & 9,5 \\
\hline \multicolumn{7}{c}{ Coeficientes de Digestibilidade $\%$} \\
\hline A (60 dias) & $59,5 \mathrm{a}$ & $74,2 \mathrm{a}$ & $55,0 \mathrm{a}$ & $62,0 \mathrm{a}$ & $42,0 \mathrm{a}$ \\
B (90 dias) & $63,5 \mathrm{~b}$ & $74,8 \mathrm{a}$ & $66,4 \mathrm{~b}$ & $55,6 \mathrm{~b}$ & $56,3 \mathrm{~b}$ \\
Coef. variação & $3,6 \%$ & $2,8 \%$ & $7,0 \%$ & $7,9 \%$ & $13,6 \%$ \\
\hline Nota. Para os coeficientes de digesläo, médias seguidas de letras desiguais na mesma coluna diferem enllie si (p< $<0,05)$. \\
\hline
\end{tabular}

\section{Tabela 3}

Nutrientes digestiveis dos fenos de cunhõ e NDT, expressos em porcentagens. Pirassununga - SP, abril/maio de 1985.

\begin{tabular}{lccccc}
\hline Estádio vegetativo & PD & FBD & ENND & EED & NDT \\
\hline Corte aos 60 dias & 16,1 & 19,0 & 18,7 & 1,4 & 57,09 \\
Corte aos 90 dias & 14,9 & 27,8 & 13,6 & 2,3 & 61,66 \\
\hline Erro padrão da média & & & & $\pm 0,8$ \\
\hline Coeficiente de variação \% & & & & 3,5 \\
\hline
\end{tabular}

Os níveis de EE dos fenos nos tratamentos A e B estão próximos aos de Katiyar et al. ${ }^{13}$ (1970) e superiores aos encontrados por Ram Ratan ef al.17 (1982) e os de Upadhyalya; Pachauri19 (1983). Quanto aos teores dos ENN do presente trabalho, estão próximos aos valores encontrados por Katiyar et al. ${ }^{13}(1970)$ e inferiores aos apresentados por Ram Ratan et al. ${ }^{17}$ (1982) e Upadhyaya; Pachauri' ${ }^{19}$ (1983).

Os CD encontrados no presente experimento mostraram que, com o avanço da idade de corte da Cunhã de 60 para 90 dias, houve aumento da digestibilidade da MS, da FB e do EE $(p<0,05)$ bem como dos NDT $(p<0,05)$, com exceção do ENN que contrariamente apresentou digestibilidade menor para o feno cortado com 90 dias. Com relação à MS, a digestibilidade foi maior para o feno de 90 dias, mas o valor encontrado foi inferior ao relatado por Katiyar et $a l .13$ (1970) e semelhante aos referidos por Ram Ratan el al.17 (1982) e Upadhyaya; Pachauri'19 (1983).

Azevedo; Morros² (1984) realizaram um ensaio de digestibilidade "in vitro" da MS do feno de Cunhã com 42, 56, 70 e 84 dias e encontraram valores bem próximos aos do presente trabalho com exceção do corte aos 84 dias, em que a digestibilidade foi menor.

A digestibilidade de FB foi melhor para o tratamento B (90 dias), talvez pelo maior tempo de retenção no rúmem-re- tículo pois esse corte mais tardio apresentou maior proporção de fibras em relação ao lèno com 60) dias de idade. Um alimento mais libroso tende a permanecer por mais tempo no rúmen (Balch's, 1950).

Os coeficientes de digestão da FB $(55,0 \%$ e $66,4 \%$ ) foram próximos aos de Katiyar e't al. ${ }^{13}(1970)(65,9 \%)$ e superiores aos de Ram Ralan ea al.17 (1982) e Upadhyaya; Pachauril' (1983).

Azevedo et al. ${ }^{3}$ (1984), em um estado da digestibilidade "in vitro" do feno de Cunhã cm diferentes estádios vegetalivos, concluíram que a leguminosa pode ser cortada até os 70 ) dias, sem prejuízos no seu valor nutritivo. () valor nutritivo foi mantido no corte aos 90 diats.

Em relação à digestibilidade da $\mathrm{PB}$. não foram encontradas diferenças signilicativas entre os dois cortes (cerca de 74,0\%), resulaado semelhante ao de Ram Ratan et al. ${ }^{17}$ (1982), de (74,4\%); superior ao de Upadhayay; Pachauri "(1983) de $(63,8 \%)$ e inferior ao de Katiyar et al. ${ }^{13}(1970)$ de $(84,4 \%)$.

Deve-se ressaltar que a ingeslão diária de proteína (182 g e $154 \mathrm{~g} / \mathrm{animal}$, respectivamente para os tratamentos A e B) provenientes dos fenos de Cunhã, foi superior às quantidades requeridas pelos ovinos (NATIONAL RESEARCHCOUNCIL ${ }^{16}, 1976$ ) de $133 \mathrm{~g} / \mathrm{ani}-$ mal, demonstrando que a referida leguminosa apresenta boa possibilidade de uso como fonte protéica de alto valor para nutrição de pequenos ruminantes.

Na Tab. 3 estão expressos os nutrientes digestíveis para os fenos de cunhã utilizados, bem como os valores de nutrientes digestíveis totais (NDT).

Para os valores de NDT, houve diferença estalística $(p<0,05)$ entre os tratamentos.

Os valores dos NDT determinados neste trabalho $(57.0 \%$ e 61,6\%) estão próximos aos de Ram Ratan et al. ${ }^{17}$ ( 1982 ) $(59,7 \%)$ e são inferiores aos encontrados por Katiyar et al. ${ }^{13}$ (1970) $(70,8 \%)$.

\section{CONCLUSÕES}

Os dados encontrados no presente trabalho permitiram emitir as seguintes conclusões:

a) A digestibilidade da MS, FB, EE e os nutrientes digestíveis totais foram elevados para o feno de Cunhã cortado aos 90 dias, comparativamente ao cortado aos 60 .

b) A digestibilidade dos extrativos não nitrogenados foi superior para o feno cortado aos 60 dias, em relação ao cortado aos 90 .

c) Pode-se recomendar o corte da Cunhã para a fenação aos 90) dias de crescimento, com base nos teores de NDT e ainda pelo fato de a digestibilidade de proteína ter sido semelhante para os dois cortes $(60$ e 90 dias). 


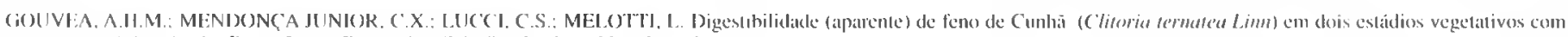

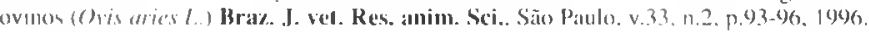

\section{SUMMARY}

Twelve crossberd rams (Ovis aries L.), 17 months old, were assigned to a completely randomized digestion trial with two treatments to evaluate apparent digestibility of cunhã hay (Clitoria ternatea $L$.) harvested at two different stages: A) 60 days and $B) 90$ days of maturity.

Digestibility coefficients of dry matter, crude fiber and ether extract, as well total digestible nutrients (TDN), were higher for the hay harvested at 90 days. However, digestibility of nitrogen free extract was better for the 60-day hay, whereas crude protein digestibility did not differ between treatments. It was concluded that Cunhã can be harvested at 90 days of growth.

\section{UNITFRMS: Digestibility; Sheeps; Hay}

\section{REFERÊNCIAS BIBLIOGRÁFICAS}

I-ASSOCINTION OF OFFICIAL ANAIYTICAL, CHEMISTS. Orlicial methods of analysis. 12.ed. Washington. AOAC. 1975

2-A\%IVEI)O. A.R.; MORROS, J.F.G. Estudo da digestibiludade "in vitro" da materias secal e matérias orgânica do fieno de Cunhã (Cliroria lernarea $l$.). In: REUNIAO ANUAL DA SOCIEDADE IBRASILEIRA DE, 7OOTECNIA, 2I, Belo Horizonte. 1984 Anais. p.311.

3-A\%FVEDO, A.R.: VIANA. O.J.: MORROS. J.F.G. Determinacão da fração librosa de Cunhã (Clitoria lematea L.) In: REUNIÄO) ANUAL. DA SOCIEDADE BRASII.EIRA DE ZOOTECNIA. 21 Bclo Ilorizonte, 1984. Anais. p.387.

4-BAIL.FY. L.H. Manual of cultivated plants. New York, Mac Milian, 1949

5-BALCII, C.C. Factors allecting the utilization of food by dairy cows. 1. Ralte of palsiage of food through the digestive tract. IBritish Journal of Nutrition. v.4. p.361-88. 1950.

6-CHAKRAVARTY. A.K. Forage production from arid deserts. Indian larming. v.20, n.9. p.15-7. 1970.

7-C 'RONQUIIS", A. The evolution and classification of llowering plants. New York, Nelson Lid, 1968.

8-CROWI)ER, L.V. C Ciroria fernated L. Duc, ats a forage and cover crop. a review. Nigerian Agricultural Journal, v.1 1, p.61-5, 1974.

9-b)ARI.INGION, J.M.: HERSBERGER, T.V. Effect of forage maturity on digestibility. intake and nutritive value of allalfa, limoty and or chard by equine. Journal Animal Science, v.27. p.1572-6. 1968

I0-(iAR\%A, R.T.; POR'TUGAL. A.Ci.: BALLESTEROS, H.W. Evaluación en pastoreo de asociaciones de zactes y leguminosals utilizando vacpuillas de razas curopeas. en clima Iropical. Tecenica l'ecuariat en Mexico, 12.23, p.7-11, 1972.

I I-coMHS. F.P. ('urso de estatistica experimental. I0. ed.Piracicaba, Nobel, 1981.

12-GilRGiEl, M.A.; FERNANDES, A.A.O. P'rogramil de melhoramento e mancjo de pastagem no Nordeste. Relatório Anual de p'esquisa da Eimpresa de l'esquisa $\Lambda$ gropecuária do C'eará. Fortaleza, 1980. p. 7-26

1.3-KNIIYAR, R.C :. RANJHAN. S.K.: SIIUKL.A. K.S. Yield and nutritive value of c'litoria rernatea - a wild peremnial legume, for sheep. Indian Journal of Dairy Science. v.23, p.79-81, 1970.

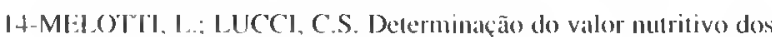
capins elegante Napjer (Pemissentum purpureum Sc/htm) efino (Brah hiaria mutica), através de ensalio de digestibilidade (aparente) com cameiros. Boletim de Indústria Animal, v.26, p.275-84, 1969.

15-MEYER, J.II.; WEIR, W.W.C.: JONISS, L.C.: IIULL. J.C. The inlluence of stage maturity on the feeding value of oalt hay. Journal Animal Science, v.16, p.623-32, 1957.

16-NATIONAL, RESEARCH COUNCIL. Nutrients requirements of sheep 5.ed. Washington, National Academy of Sciences. 1976.

17-RAM RATAN; KUNDU, S.S.; BHATIA. DR. Note on the nutritive value of C'litoria ternatea hay for sheep. Indian Journal Science. v.52, p.26.5-7, 1982
18-SANCHEZ, C.F. Estudios sobre el valor nutritivo de la semilla de ('litoria (Clitoria ternatea Limm.) México, 1969. Dissertação) (Mestrado) - Universidade Nacional Autonomal do México.

19-UPADIIYAYA, R.S.: PACIIAURI, V.C. Nulritive value of Clltoria fermatea L. hay for Barbari goats. Indian Journal Animal Science v.53. p.1032-3. 1983

20-WEIR. W.C.: JONES, L.C.: MEYER. J.H. Effect of cutting interval and slage of maturity on the digestibility and yeld of allatia. Journal Animal Science: v. 19, p.5-19, 1960.
Recebido para publicação: $24 / 08 / 94$ Aprovado para publicaçāo: 21/08/95 